\title{
Metodología de la enseñanza del español como segunda lengua
}

Ana $M^{a}$ Rico Martín

Profesora de la Facultad de Educación y Humanidades de Melilla

Univesidad de Granada. Campus de Melilla

\section{Breve introducción}

Ante todo me gustaría dejar claro el por qué de la expresión español como segunda lengua y no como lengua extranjera, a pesar de que todas las estrategias didácticas aludidas en esta ponencia del $V$ Curso de Intercultura pueden emplearse indistintamente para la enseñanza de las lenguas extranjeras y para la de segundas lenguas e, incluso, en muchos aspectos son útiles para el aprendizaje del español como lengua materna.

Hay un debate no resuelto sobre el uso de los términos segunda lengua y lengua extranjera, así no hay una opinión unánime sobre el empleo de ellos. Aunque numerosos investigadores del tema utilizan ambas expresiones para una misma realidad, habría que matizar que lo correcto en el caso de Melilla es español como segunda lengua, pues es la mayoritaria, además de oficial, de la ciudad, mas no coincide con la L1 o lengua materna de gran parte de la población que se comunica oralmente por medio de un dialecto amazige, el taqer'act (habla de la zona circundante a Melilla) dentro del tarifit (habla de las montañas del Rif).

Distinto es si nos referimos al inglés o al francés como segundo idioma que se enseña en los centros educativos, estos sí que merecen la denominación de lenguas extranjeras pues son totalmente extraños en nuestro entorno. Si cruzáramos nuestras fronteras con el reino alauita, en cualquier colegio de la provincia de Nador, por citar la más cercana, seguirían teniendo como L1 el amazige pero como L2, el asunto se complica, tendrían el árabe y el francés, la primera como lengua oficial del país y la segunda casi con la misma consideración. 


\section{2. Últimas tendencias en la enseñanza de las segundas lenguas}

Los profesores de lenguas extranjeras se han preocupado continuamente por encontrar el mejor método para su docencia, así ha surgido gran variedad de ellos, desde los que comienzan por la práctica oral para llegar al análisis de diferentes modelos lingüísticos a aquellos basados en la cuasi memorización de diálogos y textos.

Quizás, el que nos es más próximo es el llamado método estructuralista, donde a partir de la descomposición del sistema lingüístico en los distintos subsistemas (fonética / fonología, morfosintaxis...) se trabaja el aprendizaje de normas y estructuras según los criterios de complejidad de estas últimas (lo menos complejo resulta más fácil de asimilar], la frecuencia con que aparecen determinados elementos en la lengua (a mayor frecuencia el elemento es más útil), y la pluralidad de funciones (aquello con más usos debe ser aprendido antes de lo que tiene menos) (Vez 1998: 11).

Frente a esta metodología tan delimitada en cuanto al papel del profesor, del alumno y del propio material de enseñanza, y como uno de los frutos de la gran renovación educativa de la década de los setenta, surgieron los enfoques comunicativos dando un gran cambio a la didáctica de las lenguas extranjeras y de las segundas lenguas primero, de la lengua materna después. En estos momentos, se entendía el lenguaje sólo como un instrumento de comunicación, en cuya enseñanza lo importante no era conseguir una corrección formal exquisita, sino capacitar al alumno a comprender y producir mensajes en la lengua estudiada, dicho de otro modo, a comunicarse de forma efectiva en situaciones reales con hablantes nativos (Jáuregui 2000: 169).

Este nuevo método surgió del concepto de competencia comunicativa de Hymes (1972) frente al de competencia lingüistica de Chomsky, que dejaba fuera del análisis de los usos lingüísticos los problemas prácticos que aparecen en el desempeño de la lengua, derivados, ante todo, de los aspectos socioculturales de la comunicación. La definición de competencia comunicativa se refiere tanto al conocimiento del sistema lingüístico como a la capacidad para usar este conocimiento en la comunicación.

De esta forma, un alumno que sigue estos enfoques comunicativos en el aprendizaje de una $L 2$ desarrollará al mismo tiempo cuatro subtipos de competencias como bien señala Jáuregui (2000: 169-70):

- Una competencia lingüística, por la que adquiere paulatinamente un mejor dominio y corrección de los conocimientos lingüísticos.

- Una competencia sociolingüistica, que le permite adecuar su mensaje al contexto real en que lo emite.

- Una competencia discursiva, por la que produce enunciados cada vez más complejos guardando coherencia y cohesión entre sí.

- Una competencia estratégica, mediante la cual puede anticipar, evitar y resolver los problemas de comunicación que surjan. 
A partir de los ochenta y como consecuencia de la gran aceptación de la perspectiva comunicativa y también como necesidad del propio método aparecieron las tareas comunicativas que ayudaron al gran avance en la enseñanza de las segundas lenguas. Con palabras de Villalba et al. (2001: 157) definimos la tarea como "una unidad de trabajo en el aula que implique a los aprendices en la comprensión, manipulación, producción o interacción en la $L 2$ mientras su atención se halla centrada prioritariamente en el significado más que en la forma". De este modo, cualquier actividad que realicemos en nuestra vida cotidiana, cualquier situación que haya que resolver, puede constituir una tarea, desde comprar un artículo en cualquier comercio a rellenar un formulario de un determinado organismo, igualmente, actividades de lengua consideradas como tradicionales pueden ser enfocadas también desde la perspectiva comunicativista: se puede hacer un dictado de una receta de cocina que después se comentará y elaborará en clase o resumir un artículo periodistico para comparar las opiniones que sobre el mismo surjan en clase.

Si el contenido de una tarea puede ser muy variado, también lo será su tiempo de realización, hay actividades muy simples que pueden no llegar a la hora de duración y las hay que requieren varios días para completarla como puede ser la elaboración de un guión para una película, el análisis de los personajes, su rodaje y el comentario y evaluación final. La complejidad de la tarea depende del ritmo de aprendizaje de los alumnos, de lo que estos sean capaces de hacer.

Vez (1998: 21) nos señala algunos tipos sencillos que no son otra cosa que actividades que solemos hacer en el aula si tener una clara conciencia de la importancia que tienen para el desarrollo del aspecto comunicativo del lenguaje, amén de las capacidades cognitivas que requieran. Citemos algunas:

1. Para expresar una información detallada:

a. Ordenar los dibujos de acuerdo con un texto.

b. Completar con las palabras adecuadas los espacios en blanco de un texto.

c. Marcar las diferencias entre un texto y un dibujo.

d. Representar con mímica lo que dice un texto.

2. Para extraer una información selectiva:

a. Contestar preguntas sobre un texto.

b. Escribir frases que resuman los contenidos expuestos en el texto.

c. Emparejar dibujos y textos.

d. Comparar el texto con las predicciones sobre el tema que los alumnos hacen antes de la lectura del mismo.

3. Para extraer una información global:

a. Poner el título a un texto.

b. Reconstruir textos que han sido recortados y mezclados.

c. Resumir un texto en un número exacto de palabras.

Quizás, un ejemplo más claro de programación de una tarea comunicativa es el que nos muestran Villalba et al. (2001: 85-92) para la enseñanza del español como L2 con esta serie de actividades: 
1. Definir las situaciones comunicativas más habituales con las que el estudiante se puede encontrar: el colegio, la casa, la calle, juegos y relaciones con los amigos, aficiones, viajes, vacaciones y sentimientos.

2. Analizar las distintas situaciones: interlocutores, contexto de situación, tema, canal e intención comunicativa.

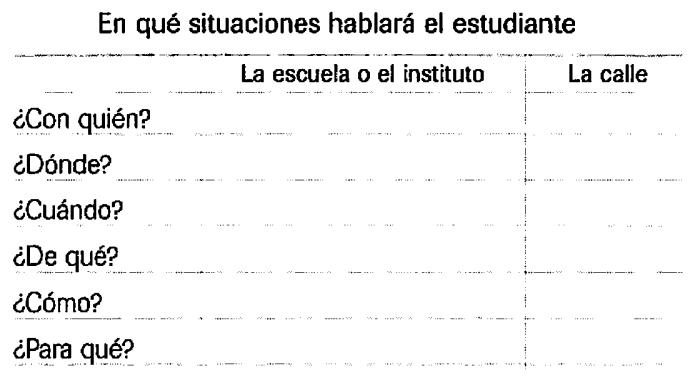

3. Seleccionar funciones en virtud de diferentes criterios: necesidad inmediata, utilidad, rentabilidad...

a. Dar y pedir información sobre uno mismo y los demás.

b. Expresar acuerdo y desacuerdo.

c. Referirse a acciones y situaciones del pasado.

d. Pedir, conceder y denegar permiso...

4. Definidas las funciones hay que precisar las nociones (temas) que se van a trabajar: en la función de pedir información sobre la ubicación de lugares y servicios se trabajará un léxico relacionado con los lugares a los que habitualmente necesiten acudir los estudiantes.

5. Plantear una secuenciación de actividades comunicativas que vayan desde una producción más controlada a otra más libre: de un trabajo precomunicativo a una comunicación auténtica.

Realizada la actividad, hay que evaluar la actuación de los alumnos para asegurarnos su papel activo en este tipo de enseñanza-aprendizaje. Debemos analizar sus capacidades interpretativas y productivas, de fluidez verbal, de adecuación al contexto, de corrección lingüística..., es decir, todo aquello que refleje una buena competencia comunicativa. Vez (1998: 30) nos facilita esta evaluación a través de una tabla que mide el perfil comunicativo de los alumnos: 
Amplitud:

Extensión de los enunciados producidos o comprendidos.

\section{Complejidad:}

Hasta qué punto comprende o intenta producir construcciones complejas.

Variedad:

Qué diversidad de destrezas. funciones y registros es capaz de manejar.

\section{Fluidez:}

Qué facilidad de habla / respuesta y de producción escrita posee.

\section{Flexibilidad:}

Habilidad para una buena adaptación a cambios en el tópico o tarea.

\section{Corrección:}

Hasta qué punto domina los aspectos formales de la lengua y la corrección de la información que transmite. Propiedad:

Hasta qué punto sus enunciados son adecuados para la situación y los significados que pretende transmitir. Independencia:

El grado de autonomía de información con respecto a sus interlocutores.

\section{Clarificación:}

Hasta qué punto necesita que se le aclare o amplie un enunciado o un segmento de un discurso. Vacilación:

Hasta qué punto duda antes de hablar / escribir y mientras que está hablando o escribiendo

Cuadro adaptado de B.J. Carroll

Para cerrar este apartado hagamos un breve resumen de lo que supuso la nueva metodología de los enfoques comunicativos frente a otra más tradicional:

- El énfasis de este tipo de enseñanza-aprendizaje se centra en su propio proceso interactivo y no sólo en la materia (los contenidos lingüísticos), como se hacía hasta entonces cuando se determinaban claramente qué es lo que había que aprender, cómo y con qué materiales.

- El contenido de aprendizaje parte, a un mismo tiempo, del profesor y del alumno, de la negociación entre ambos. Esto favorece la motivación en la enseñanza al considerarse los intereses, las necesidades y las aficiones del segundo por encima de todo.

- Se trata de trabajar lo que la lengua es para el alumno, por tanto, los objetivos serán definidos a posteriori contando con su opinión, pero siempre a través de trabajos que se asemejen lo más posible a la vida real, con lo que propiciamos el aprendizaje significativo $y$, por tanto, efectivo.

- La evaluación, antes de centrarse en el dominio de la lengua (evaluación de logros y evaluación de conocimientos), se orienta al proceso, en los criterios de éxito a lo largo del mismo (evaluación formativa). Si bien en métodos anteriores se penalizaban los errores considerándolos sólo desde la perspectiva de error-sanción, en este sistema el error es, en general, constructivo, marca un paso adelante en el proceso de aprendizaje que va rehaciendo el alumno. 
- Por último, el profesor es considerado como guía o facilitador del proceso de comunicación. Trabaja con el alumno y no en lugar de él, organiza los textos y las tareas, analiza las necesidades del alumno y le aconseja.

No obstante, ante el relieve y trascendencia que tienen estos enfoques comunicativos no faltan voces críticas por la insistencia del método en los aspectos orales de la lengua que lo llevaron al tratamiento casi exclusivo de la lengua oral. Esto provoca frecuentes errores en la expresión escrita como el uso incorrecto de tiempos verbales, de conectores y preposiciones, de estructuras sintácticas complejas... y toda una lista de incorrecciones que señalan García Valle y Ricós Vidal (2000: 99-110) para concluir en que lo eficaz es la mezcla de métodos antes de usar sólo el comunicativo o el estructural.

\section{Algunas nociones didácticas para trabajar los distintos aspectos lingüísticos del español como 12}

En primer lugar, considero necesario hacer la siguiente observación:

Para este apartado y en las sugerencias de estrategias y actividades que se harán a lo largo de este curso lingüístico, muchas veces no se establece una separación taxativa entre objetivos de Ed. Infantil y Primaria o entre ésta y Secundaria porque los criterios de actuación pedagógica que se proponen para las diferentes etapas educativas responden a principios comunes y, por tanto, más que en la cualidad de sus planteamientos se diferencia en los ritmos y materiales de su aplicación.

Una segunda aclaración es que seguiremos sobre todo las pautas metodológicas que señala Ruiz Bikandi (2000) añadiendo y comentando aquello que creamos más conveniente para la enseñanza del español a alumnos de habla amazige y así atraer hacia nuestro entorno teorías más generales no por ello poco interesantes.

\subsection{La lengua oral}

El poco dominio de una lengua no sólo se refleja en su uso oral sino que también interviene la edad del hablante, a menor edad los registros lingüisticos y los tipos de discursos están muy limitados. En el momento en el que el niño empieza a adquirir el español como segunda lengua en el colegio avanza de igual manera en su lengua materna, va rellenando las lagunas que tiene en ella mediante la adaptación o adecuación de lo aprendido en español.

Lo primero que debemos fomentar en el alumno es la comprensión oral, es decir, la escucha, esa habilidad tan fácil de explicar y tan difícil de mantener pues intervienen factores emocionales y cognitivos que la hacen ser muy variable. Por esta razón, debemos comenzar con la práctica de escucha de textos orales, pero teniendo en cuenta sus distintos grados de dificultad, lo haremos por los más fáciles, es decir, por aquellos que tengan las siguientes características (Ruiz Bikandi 2000: 171):

- Número limitado de personajes.

- Personajes planos, es decir, sin profundidad psicológica y claramente distintos.

- Relaciones espaciales simples: una calle, un pueblo y no "un poco más lejos". 
- Respetar el orden cronológico de los acontecimientos.

- Relacionar los diferentes enunciados, por ejemplo como la relación causa-efecto o motivos-meta.

- Posibilidad de relacionar fácilmente la nueva información con los conocimientos anteriores.

No es necesario meditar mucho acerca de qué textos poseen todas estas cualidades: el cuento, o pequeños relatos que iremos adaptando a la edad y ritmo de nuestros alumnos. Dejemos ahora la escucha y pasemos al habla. Si es difícil para nosotros expresarnos oralmente en público en nuestra propia lengua, pensemos en las barreras que encontrarán estos jóvenes para hablar en español teniendo en cuenta el gran peso del amazige en el hogar familiar -es la única lengua en que se expresan muchas madres, la única que conocen- y su entorno más cercano, sobre todo en aquellos barrios en los que constituyen la población mayoritaria, si no exclusiva, donde tienen poca posibilidad de usar el español en sus relaciones interpersonales.

Los errores que presentan son:

- Falta de automatización y, como consecuencia, de fluidez verbal.

- Escaso conocimiento léxico y morfológico. De aquí que se recurra a numerosas actividades para el desarrollo del vocabulario.

- Lagunas en la formulación sintáctica de las ideas, tienen problemas con los conectores y con la coherencia y cohesión de los enunciados, expresándose, como se dice familiarmente, de forma telegráfica - como los "indios"-.

La solución a los mismos es hacerles hablar y hablar, producir frecuentemente, en un principio imitando modelos, generar situaciones en las que todos participen, es decir, no deben hablar sólo para el docente pues provocaría el aburrimiento y la falta de escucha de los compañeros, sino que se negociarán los temas y se variarán los turnos de palabra. Nuestros alumnos, mientras hablan, van despertando la conciencia sobre lo que dicen, sobre los problemas de expresión que les van surgiendo y la forma de solucionarlos, es decir, prueban hipótesis sobre el español L2 en la práctica continua, si resultan efectivas con los interlocutores las hacen suyas para siempre, si fracasan las desechan y formulan otras nuevas. Es el mismo proceso gemelar que cualquier niño pequeño realiza al adquirir el lenguaje: elaboración de reglas y prueba de hipótesis.

De igual forma que los niños pequeños pasan por una fase de silencio alrededor de los dos o tres años de edad mientras observan y analizan lo que sucede en torno a ellos, el aprendiz de L2 hace algo similar: de emplear su lengua materna en situaciones escolares en las que debiera usar el español -cuántas veces se lo recriminamos en las aulas-, pasa por esa fase de silencio para acabar con una producción más rica en lengua española. Nuestra experiencia docente nos llevará a presentarles tareas de habla muy fáciles -por ejemplo, contextualizadas en el aquí y ahora, en la acción, con recursos visuales, en intervenciones breves y dialogadas- para acabar con los usos más formales que son los que más les cuesta: sin apoyo contextual ni extralingüístico, referidos a hechos pasados o hipotéticos, en intervenciones de mayor duración y monologadas. 
Presentamos seguidamente una serie de actividades discursivas de uso diario que constituyen intercambios comunicativos y que hemos recogido de Ruiz Bikandi (2000: 182-85):

1. Etiquetar. poner nombre a los objetos del mundo. Es un mecanismo básico para establecer el tema conversacional, por eso es una actividad que ocupa buena parte del tiempo en los primeros pasos de la L2: nombrar en imágenes, murales, fotografías, el aula... para ello debe conocer bastante vocabulario español.

2. Hacer recuentos: narrar, basándose en el diálogo, experiencias compartidas por todos los presentes. Este tipo de conversación se basa en el recuerdo conjunto de hechos vividos, cuyo comentario es conducido por el profesor. Al principio se pueden apoyar en imágenes que poco a poco se irán abandonando.

3. Contar relatos de ficción: narraciones donde algún ser animado enfrentado a un problema pasa por una serie de acontecimientos que le conducen a una meta. Los cuentos infantiles constituyen un marco idóneo para ello, además son fáciles de dramatizar o para memorizar y oralizar pequeñas frases. Irán creciendo en complejidad con el avance de los niños.

4. Relatar acontecimientos: los niños relatan acontecimientos vividos o hechos conocidos que sus interlocutores desconocen. Requiere apoyo del docente para, a través de preguntas, ayudar al hablante a organizar y establecer con claridad los parámetros del mundo que está refiriendo. Su uso es muy frecuente en Educación Infantil y en Primaria y decae con los mayores, un grave error pues es éste el tipo de habla que mejor entrena en el relato, la interpretación y la escucha de experiencias de la vida real, tan fundamentales en la comunicación humana.

5. Predecir acontecimientos: entrena en la elaboración de hipótesis y planes. A diferencia del anterior, la predicción implica basarse en los conocimientos actuales para proyectarlos hacia el futuro, hipotetizando y valorando lo posible y lo probable. Por otra parte, ofrece la posibilidad de usar y entrenarse en ciertos tiempos y modos verbales (futuro, condicional y subjuntivo). Tareas propias para la Educación Infantil serían predecir actividades del día, especular sobre el curso de una narración o cuento o predecir el tiempo del día siguiente. En Educación Primaria la típica redacción con inicio "qué hubieras hecho tú si..." ayuda al descentramiento y a la consideración de los sentimientos y pensamientos de los demás.

6. Buscar significados: los adultos infieren para los pequeños lo que quieren dar a entender, interpretan su conducta o piden explicaciones sobre lo que se ha querido decir.

7. Explicar: responder a un "¿cómo?" o a un "¿jpor qué? Aunque es un discurso muy frecuente en el aula, precisa más entrenamiento que la narración porque en la explicación el hablante no dispone de un soporte temporal en el que apoyarse. Explicar apoyándose en la acción facilita las cosas, por eso, los docentes expertos explican a los niños uniendo la palabra a la acción y reclaman de ellos explicaciones pautadas para las cuales pueden apoyarse en actos o en imágenes. 
Ante estas actividades de los alumnos el papel del docente tiene gran relevancia, a la hora de fomentar el habla en clase debe emplear diferentes estrategias fruto de su experiencia y creatividad: orientará la conversación por medio de preguntas y comentarios abiertos que inciten al alumno, le ayudará a completar detalles, a precisar su información cuando sea demasiado vaga, sugerirá que explique y justifique las acciones relatadas. No en vano, el habla del profesor será tomada, en todo momento, como modelo, por tanto, deberemos preocuparnos en transmitir la lengua mediante discursos variados y con la mayor corrección posible, siempre a la altura de la capacidad perceptiva y comprensiva de nuestros pupilos. Además, estos estarán pendientes de nuestras estrategias de apoyo como gestos, exclamaciones y actitudes que demuestren la atención que les prestamos.

Si retomamos unas páginas anteriores donde advertíamos que las tareas comunicativas podían ser muy sencillas y se irían complicando a medida que lo hacía la competencia comunicativa de los alumnos, de igual forma podemos hacerlo con actividades de expresión oral:

En una fase inicial se puede obedecer órdenes de dificultad creciente o descubrir y reparar errores en la narración de un cuento conocido; en una fase intermedia, se puede explicar el contenido de unas viñetas y responder preguntas sobre ellas o exponer de forma diferente lo dicho por otros; $y$, complicando algo la tarea, en una fase avanzada se pueden transformar historias a partir de elementos nuevos o contrastar las informaciones tomadas de dos fuentes distintas.

\subsection{La lectoescritura}

Si para aprender a escribir la lengua materna es necesario un conocimiento previo de la misma, obviamente, lo mismo se puede asegurar respecto al español como L2. El problema es que no se ha llegado a determinar qué grado de conocimiento es el necesario.

No obstante, en lo que sí estaremos todos de acuerdo es en que el aprendizaje de la lengua oral y la lengua escrita deben ir paralelos, siempre posibilitando el contexto y valorando los errores constructivos.

El método que emplearemos pertenece a la decisión propia de cada docente y ahora no vamos a entrar en discusiones sobre si el global o analítico es mejor que el sintético o a la inversa. Podemos aclarar que si bien un método de procesamiento descendiente (analítico) puede resultar más motivador para el alumno al trabajar directamente con pequeños textos y palabras conocidos por él, puede llevarles a dificultades a la hora de la descodificación fonológica de un texto para su lectura, de la misma forma tendrá mayores problemas ortográficos que si hubieran aprendido con un método de procesamiento ascendente (sintético). Lo más eficaz, en realidad, lo que se hace en las aulas es la enseñanza de la lectoescritura siguiendo un método mixto.

Para clarificar estos dos tipos de procesamientos y operaciones mentales básicas en la lectura mostramos el siguiente cuadro de Ruiz Bikandi (2000: 221): 

(procesos de alto nivel)

\begin{tabular}{l|l|l} 
& AEXTO & - Formulación y verificación de hipótesis \\
PÁRRAFO & - Anticipación \\
- Acceso lexical & FRASE & - Construcción de expectativas e indiferencias \\
- Reconocimeto de palabras & PALABRA & - Compresión \\
- Descodificación & LETRA & - Interpretación
\end{tabular}

Acerca de la enseñanza de la lectura en lengua materna y en segunda lengua, investigaciones realizadas al respecto han demostrado que las estrategias que emplean los neo-lectores son las mismas en ambos casos, independientemente del tipo de escritura que tengan ambas lenguas. Pero esta aseveración no nos vale en nuestro contexto pues el amazige es una lengua oral -al menos así es entendida por sus hablantes que no conocen su escritura tifinagh ni su transcripción moderna neo-tifinagh, empleada sólo por los estudiosos de la lengua- y nuestros alumnos de origen bereber nunca han tenido la experiencia previa de aprender a leer en su lengua materna.

Por otra parte, los factores culturales también intervienen en el proceso lectoescritor, tengamos en cuenta que la cultura bereber es muy diferente a la española. Si consideramos dos casos de emigrantes, un niño melillense, con español como $L 1$, que va a vivir a Tarragona y una niña campesina marroquí que se traslada al mismo lugar, el primero sólo tendrá problemas con la lengua catalana - que no son pocos- pero la marroquí tendrá dificultades además con una cultura muy diferente a la suya, agravadas también por el mero hecho de ser de sexo femenino - no en nuestra comunidad sino en la suya-. Si para enseñarles el catalán recurrimos a textos sobre fiestas españolas y catalanas como la Navidad o los Carnavales - por poner dos ejemplos recogidos en el currículum escolar- primero deberemos enseñarle el valor de estas celebraciones dentro de nuestra cultura.

Retomando la habilidad lectora en español L2 que precisan nuestros alumnos, queda decir que ésta depende del dominio lingüístico que manifiesten: una mala lectura es consecuencia de un desconocimiento de las estructuras sintácticas y del léxico de nuestra lengua. Por ello Ruiz Bikandi (2000: 240-44) aconseja lo siguiente:

- Trabajar el reconocimiento automático y exacto de las palabras, condición sine qua non para una lectura fluida.

- Los textos empleados deberán tener un nivel lingüístico igual o inferior al que posee el lector, además serán variados e interesantes. Se comenzará con textos fáciles para adquirir facilidad de lectura a primera vista de palabras y expresiones de la lengua. 
- Se precisa un vocabulario receptivo masivo para comprenden mejor los textos, para esto desarrollaremos el vocabulario en L2 de forma sistemática: palabras clave, campos semánticos...

- Dedicar mucho tiempo y estrategias para la lectura descendente y ascendente y para el conocimiento de formas gramaticales y léxico.

- Esquematizar el contenido del texto y representarlo de distintos modos: en árbol, redes, mapas semánticos... durante la lectura.

- Adecuar el espacio y organizar el tiempo de modo que la lectura tenga una presencia central en la clase.

\subsection{La lengua escrita}

Uno de los objetivos fundamentales de la escolarización es el dominio de la lengua escrita y lo que llevó a plantearnos como docentes esta ponencia con título "Metodología de la enseñanza del español como segunda lengua" fueron las dificultades y los errores que presentan nuestros alumnos bereberes en sus producciones escritas en español.

Si en el epígrafe anterior asegurábamos que el proceso lector era el mismo en L1 y en L2, podemos decir lo mismo en el proceso de la escritura. Relacionado con esta cuestión se suelen hacer dos grupos de los alumnos:

- Los que aprenden a escribir en la segunda lengua y más tarde aprenden en la materna. Pensemos en ese alumno emigrante de Educación Infantil que aprende a escribir en catalán en el colegio y luego le enseñan en español, la lengua de casa.

- Los que aprenden a escribir en su lengua materna y más tarde lo hacen en la segunda. Imaginemos ahora el caso de un joven andaluz de once años que emigra a Cataluña, anteriormente ya había aprendido a escribir en español y ahora le toca hacerlo en catalán.

Estos dos chicos tienen la dificultad de aprender una nueva lengua -más el segundo que el primero-, pero si los comparamos con un alumno bereber con lengua materna amazige y segunda lengua española, éste es el que encontrará una barrera mayor para aprender nuestro idioma. No lo podríamos incluir en ninguno de los dos grupos anteriores por lo que toda esa literatura que existe sobre ello no nos vale: nuestro alumno no recibe ningún input escrito de su entorno más próximo al ser su lengua oral, carece de toda incipiente capacidad de desciframiento de lo escrito y nunca se ha planteado las hipótesis primarias que hacen los niños al comenzar la escritura (hipótesis del nombre, hipótesis de la cantidad mínima de grafía e hipótesis de la variabilidad mínima de las mismas].

Además de esto están los factores culturales que mencionamos en la lectura pero que en lo específico de la escritura se refieren a la consideración tan distinta que tiene la expresión escrita en las sociedades industrializadas del primer mundo y en las sociedades rurales del tercero.

Cuestión aparte es el concepto de la escritura que tiene un escritor hábil y el de un escritor inexperto como pudiera ser cualquier alumno nuestro. El primero sabe que escribir es algo más que trasladar al papel meras palabras, el proceso escribano supo- 
ne pensar en el contenido, organizar ideas, escribirlas, leer, releer y reescribir el texto... una tarea bastante compleja. Un escritor que, sólo por el poco dominio de la lengua española, puede considerarse inexperto, planifica poco el texto, da menos importancia a las ideas que a las formas lingüísticas, su escritura no está automatizada y realiza más pausas que quien escribe en su lengua materna, no produce borradores sobre lo escrito $y$, por tanto, se corrige menos, a pesar de ocuparle más tiempo sus composiciones son más breves y en muchos casos reflejan interferencias, ya fonéticas ya morfosintácticas, de su lengua materna. Al final, probablemente sus textos sean comprensibles pero no adecuados a la práctica comunicativa.

Ante estas dificultades debemos tener presente lo siguiente (Ruiz Bikandi 2000: 302-07):

1. Hay que dejar tiempo suficiente para que los alumnos escriban, pues se trata de una actividad de por sí compleja y aún más para ellos.

2. Las actividades de escritura deben entenderse como de uso lingüístico en su globalidad, sin olvidar los elementos pragmáticos, holísticos, estratégicos de la comunicación.

3. Basaremos toda nuestra metodología en situaciones reales de escritura para que el aprendizaje resulte significativo, conviene escoger los temas de entre los vividos en el aula y, por tanto, en L2.

4. Les facilitaremos estrategias de ayuda para que los mismos alumnos puedan resolver los problemas de escritura que se les presenten.

5. A través de las actividades intentaremos siempre propiciar la reflexión sobre el uso de la lengua.

6. Como actividad comunicativa que es la escritura, elaboraremos actividades que demuestren el carácter social de esta destreza teniendo en cuenta los destinatarios de las mismas.

7. Les facilitaremos la adquisición del vocabulario mediante recursos variados como pueden ser los diccionarios, ficheros léxicos, murales de aula, etc.

Por último, no estaría de más señalar las dificultades de estos alumnos a los que se dedica el curso relacionadas con su competencia gramatical, dificultades referidas al escaso dominio de la lengua española y debidas fundamentalmente a dos causas. La primera de ellas se refiere a que se hallan a medio camino de adquirir el español y la segunda viene de que su lengua materna influye en gran manera en la producción en español que realizan. Constantemente van comparando de forma intuitiva ambos sistemas y transfieren elementos lingüísticos de aquel que dominan al que están adquiriendo. por ello es de gran ayuda conocer mínimamente los microsistemas de su lengua materna para identificar la naturaleza de sus errores y corregirlos:

El origen de la confusión de estos hablantes de las vocales /e/-/i/: carpentería, mircadello (mercadillo) y $/ 0 /-/ \mathrm{u} /$ : mocho (mucho), morta (multa) o el de la dificultad de pronunciación de nuestra ñ: anio (año), panuelo (pañuelo), tiene fácil explicación si conocemos un poco la fonética del amazige. Esta lengua carece del fonema nasal palatal español y la /e/ es una vocal muerta, prácticamente no existe sino que sirve de apoyo para la articulación de determinadas secuencias consonánticas, igualmen- 
te la /o/ es ajena a esta lengua aunque aparezca en algunas voces amaziges por préstamos de otras lenguas. La solución a estos errores de pronunciación pasa por el desarrollo del oído fonemático del alumno, por trabajarles la percepción y discriminación auditiva, poco a poco tenderán a desaparecer, aunque en algún caso puede quedar algún error fosilizado.

Éstas han sido, pues, algunas pautas metodológicas para una efectiva enseñanza del español como segunda lengua en alumnos de habla materna amazige. La lengua es un sistema muy complejo y comprende varios subsistemas que aquí apenas hemos tocado, abarcarlos todos en el tiempo destinado a esta ponencia sería una tarea imposible por lo que nos hemos dedicado a dar estrategias algo generales pero muy útiles para el aula. 


\section{Bibliografía}

- ALONSO, Encina (1998): ¿Cómo ser profesor/a y querer seguir siéndolo? Madrid: Edelsa-Didascalia.

- CARROLL, B. J. (1980): Testing Communicative Performance. London: Pergamon Institute.

- COPERIAS, M. José; REDONDO, Jordi y SANMARTíN, Julia (eds.] (2000): Aprendizaje y enseñanza de una segunda lengua. Valencia: Universidad de Valencia.

- GARCIA SANTA-CECILIA, Álvaro (1995): EI curriculo de español como lengua extranjera. Madrid: Edelsa-Didascalia.

- GARCÍA VALLE, Adela y RICÓS VIDAL, Amparo (2000): "Hacia una formación lingüistica integral en la enseñanza del español como L2" en Coperías, M. José: Redondo, Jordi Y Sanmartín, Julia (eds.): Aprendizaje y enseñanza de una segunda lengua. Valencia: Universidad de Valencia.

- HYMES, D. (1972): "On communicative competence", en J.B. Pride y J. Holmes [eds.] Sociolinguistics: Selected Readings. Harmondsworth: Penguin Education.

- JÁUREGUI ONDARRA, Kristi (2000): "La destreza auditiva dentro de un marco interactivo" en Coperías. M. J.; Redondo. J. y Sanmartin, J. (eds.): Aprendizaje y enseñanza de una segunda lengua. Valencia: Universidad de Valencia, pp. 151-176.
- MUÑOZ LICERAS, J. (comp.) (1992):

La adquisición de las lenguas extranjeras. Madrid:

Visor.

- PADILLA GARCÍA, Xose A. y BAIXAULI FORTEA, Inma (2000): "Dos procesos en contraste: adquisición de L1 y L2" en Coperias, M. J.: Redondo, J. y Sanmartín, J. (eds.): Aprendizaje y enseñanza de una segunda lengua. Valencia: Universidad de Valencia, pp. 151-176.

- RUIZ BIKANDI, Uri (ed.) (2000): Didáctica de la segunda lengua en educación infantil y primaria. Madrid: Sintesis.

- STERN, H. H. (1970): Perspectives on second language teaching. Toronto: Ontario Institute for Studies in Education.

- VEZ, José Manuel (1998):

Didáctica del E./L.E. Teoria y práctica de su dimensión comunicativa. Granada: Grupo Editorial Universitario.

- VILLALBA MARTÍNEZ, Félix: HERNÁNDEZ GARCÍA, M. ${ }^{\circ}$ Teresa y AGUIRRE MARTÍNEZ, Carmen (2001): Orientaciones para la enseñanza del español a inmigrantes y refugiados. Madrid: MECD. 